\title{
An existential theory of truth
}

\author{
Dale Cannon \\ Western Oregon State College, USA
}

\begin{abstract}
This article is an attempt to present a simplified account of the theory of truth expressed in the writings of certain existentialist writers - namely, Kierkegaard, Heidegger, Jaspers, and Marcel. It is designed to serve as a supplement to conventional textbook treatments of the nature of truth, which typically ignore the contributions that existentialists have made to the topic. An existential theory of truth stresses the epistemological (not ontological) indeterminateness of meaning and truth, apart from one's personal participation in determining them.

Contrary to superficial interpretations, this theory does not do away either with a transcendent reality or with objectivity. What is rejected is anything that would circumvent the necessary task of participating, oneself, in the epistemological determination of truth.
\end{abstract}

\section{PREFACE}

I find it remarkable that mainstream introductory textbooks in philosophy that attempt to be comprehensive - including those which attempt to cover continental as well as Anglo-American philosophy - continue to ignore the distinctive contributions that existentialists have made to the discussion of the nature of truth. I have in mind particularly the contributions of Kierkegaard, Heidegger, Jaspers, and Marcel. ${ }^{1}$ Nietzsche's discussion of truth, if he can be regarded as an existentialist, has increasingly been brought into discussion. Occasionally, though often in the most contextless and distorting way, Kierkegaard's alleged claim that 'truth is subjectivity' is brought into discussion under philosophy of religion. But never are any of the key 
ideas of the existentialists regarding truth brought squarely into the discussion of epistemological issues. Even less do you hear of their ideas in textbook surveys of epistemology. ${ }^{2}$

This disturbs me. It disturbs me for three reasons:

- students with an interest in epistemological issues are in effect denied access to significant discussions of these issues;

- significant and insightful ideas about epistemological issues are in effect debarred from the philosophical arena of discussion; and

- the principal philosophical positions given contemporary credence are not forced to answer to all of the significant arguments to the contrary.

It is not the case that existentialist discussions of the nature of truth have been carefully examined by mainstream Anglo-American philosophers, refuted, and rightfully dismissed from further serious discussion. Rather, it has been the case that no careful examination has been undertaken in the first place - due to cultural prejudice, philosophical presumption, and/or lack of patience in empathizing with presuppositions different from one's own.

What I am attempting to do here is to articulate in rather simple terms what I have come to understand to be the existentialist theory of truth. Strictly speaking, it is only an existentialist theory of truth, one among others. I do not wish to undertake a discussion of nuanced differences between existentialists in their discussions of truth. What I present is an idealized reconstruction that I hold to be generally representative of several of the existentialists. My intention is to sketch out clearly the general kind of alternative conception of truth developed by the existentialists. An ulterior intention of this paper is to compose a straightforward account of the existentialist theory of truth which could serve undergraduate students as a supplement to text readings on conventional theories of truth. I especially solicit constructive critical response that might help this intention be more fully realized.

A final prefatory comment that does begin to draw distinctions between some existentialists: most philosophers superficially acquainted with existentialism appear to have taken Jean-Paul Sartre's popular account of existentialism - variously titled in English 'Existentialism,' 'Existentialism and Humanism', and 'What is Existentialism?' - as definitive of the movement, and Sartre's own views elaborated in Being and nothingness and elsewhere as basically representative of the other members of the movement. That is to be misled, for Sartre's views are in several repects not representative. Sartre never did take up a discussion of the nature of truth at any length in the works published in his lifetime, and what is implied about the nature of truth in his writing is not representative of other existentialists. Recently, a posthumously published manuscript entitled Truth and Existence has made clear that he did 
develop a theory of truth, but its unrepresentative status regarding the views of other existentialists remains true. The point I wish to make is that the existential theory of truth I here articulate does not presume to represent Sartre's views - or those of anyone else who happens to agree with Sartre in the relevant respects. On the contrary, it is an attempt to represent the views of certain existentialists other than Sartre, views which avoid the contradiction in which I believe Sartre's views are caught. ${ }^{3}$

\section{THE EXISTENTIALIST APPROACH TO THE QUESTION OF TRUTH}

Where does an existentialist reflection on truth begin? It begins with a shift of attention and emphasis from what is customary in conventional approaches, whether realist, idealist, or pragmatist: from a focus on what to a focus on how, from concentrating on objective content to concentrating on the mode and manner in which we are related to that content and on the ways in which the mode and manner of our relationship is reflected in how that content is conceived. Existentialists are keen to point out that how we think of something, how we conceive of it and represent it, always reflects a certain way of taking up a relationship to the thing. For example, how we think of a thing may express a relationship of indifference, of taking it for granted, of solicitude, of care to be as faithful as possible, of endeavour to let it be seen and understood on its own terms, et cetera. This is lost sight of when we mistake our representation of the thing for the thing itself or suppose we have nothing to do with anything except representations.

Take note of the form of articulation customarily used by conventional approaches: almost invariably they write in the grammatical third person, an externalizing, objectifying mode. And what they write about is written about as if it made perfect sense, regardless of how anyone may be related to it and as if it were (or could be) unproblematically ascertained to be true in general, by and for nobody in particular.

Reflect for a moment on the process of making sense of things and finding things out for yourself concretely in the first person. For something finally to make sense, it must at least make sense to you (ie you must make sense of it) and for something to be recognized to be true, it must finally be recognized to be true by you. No one else's efforts to determine truth or meaning can suffice for you - apart from your own accreditation in the present of that person'a efforts, otherwise all you have is the other person's allegation that something is so. You yourself must get in the act and risk your own powers in determining the meaning and truth of the matter in question. 
But most conventional modern approaches to truth (certain American philosophers like James and Dewey excepted) curiously leave this first-person, existential dimension out of account. Attention in such approaches is directed outward in the third person, outward upon a perfectly definite object or state of affairs on which (for realists at least) human claims presume to bear, and outward as well upon the perfectly determinate claims or propositions whose truth is under consideration. There is no uncertainty as to what these things mean. Nor is there any serious question that a given statement meets or fails to meet the supposedly perfectly definite criteria that are supposed to determine its truth. That these matters are (or can be made) entirely clear is taken for granted. Inquiry, in consequence, is imagined to be a more or less linear activity, everywhere having the possibility (in principle) of a clear and visualizable prospect - with none of the uncertainty, unclarity, and dialectical round-aboutness that plagues ordinary folk who must go about things concretely. Indeed, the conventional, modern, philosophical picture of the situation leaves no room for personal determination of meaning and truth at all. It conceives the knowing mind in Cartesian fashion as set off from a determinate external world it can at best relate to only in a detached manner, fashioning clear and distinct (ie, wholly determinate in meaning), third-person, hypothetical representations of the world to be submitted to impersonal testing as to their determinate truth status.

Conventional approaches assume that raising the question of truth in this 'objective' fashion ( $\mathrm{i} e$ in the third person and in a manner such that all things are assumed to be perfectly determinate) leaves nothing essential out of acount that might be identified by raising it in any other way. Specifically, they assume that to raise the question of truth in the first person - that is, for me to raise it for myself, or for you to raise it for yourself - involves nothing essentially different from raising it in the third person.

Yet for us in the first person singular - to begin with, anyway - nothing given is ever perfectly definite or ever perfectly certain. For something epistemologically to become definite (as distinct from ontologically definite), you and I must get into the act and interpret it in some measure and render it determinate. It only becomes epistemologically determinate (if only determinately indeterminate) as you and I render it so, deciphering its meaning. This is the case even when it is a meaning which will turn out to be 'entirely determined' in terms of certain rules.

This epistemological indeterminateness of meaning and truth, apart from our first personal participation that is lost sight of and covered over by conventional approaches, is the principal issue over which the existentialists part company with them. To proceed as if it can be ignored is to presume to step outside human finiteness; it is to presume to occupy a divine perspective. For existentialists are concer- 
ned to have us raise the question of truth in the first person singular (me for myself and you for yourself). Indeed, they contend that there is no other authentic way to raise it and that to presume to treat the question of truth in the third person in the conventional manner is already, though inauthentically, to have resolved for oneself the most important issue by default - as if one could escape the finitude of an individual human perspective and the unavoidable existential tasks of deciphering for oneself what is meant and ascertaining for oneself what is true. To treat the question of truth in the conventional way is to lend one's personal capacity for determining meaning and ascertaining truth to the support of abstract 'objective' representations (in propositional form) of the way things are, second-hand representations that belong to no one in particular and are supposed to suffice for everyone in general. Indirectly, it is to lend personal, existential support to the idea that there is no point or need to devote personal attention to the determination of meaning and truth, no need to establish access to the matters in question for oneself.

\section{DEFINITIONS OF TRUTH}

So far as they have any truth to them at all, behind and beneath all such 'objective' representations that appear to assert themselves is the participation of someone (and ultimately you and me) who accredits them, someone who asserts them, if you will. The 'objective form' of the represention leads one to lose sight of and forget this essential, first-person participation. The 'objective form' gives the impression that the asserter, validator, and critic of the representation are absent from the scene and that they can innocently be ignored. In a certain sense, of course, it is as if they are absent and can functionally be ignored. As a result, truth gets defined, for the realist, as a relationship of objective correspondence between the representation and the state of affairs it purportedly represents - for the idealist, as a relationship of objective coherence between the the representation and the systematic totality of serious representations not at the moment in question, and for the pragmatist as a relationship of objective coherence among actions guided by and experiences interpreted by the representation. In each case, truth becomes a function of a third-person relationship between the 'objective' representation and something else, an impersonal relationship which is supposed to hold regardless of the disposition of the persons involved, regardless of whether anyone is bothering to establish that the relationship actually holds.

Now, because an 'objective relationship' in this sense is already determinately what it is, already an accomplished fact, not needing anyone to determine and acknowledge it to be the case, the notion of truth as an 'objective relationship' of one 
sort or another is of no relevance whatsoever to someone who is in the process of attempting to make sense of and ascertain truth at first-hand. When little or nothing in the circumstance is clear and determinate, a criterion of truth that can only be applied to clear and determinate factors is worse than useless. On the contrary, the issue for someone in that circumstance is one of passionate care: how to move to a state of clarity from one that is unclear; how to uncover what is covered over; how to move to discovery when all you have are vague clues and hints; how to move from a situation of ignorance into a relationship of first-hand acquaintance with - and understanding of - the reality or state of affairs as it really is. From the perspective of the finite human being who is concretely attempting to determine meaning and ascertain truth for himself, truth would be such a self-determined relationship of deepening rapport with reality as it really is. Indeed, say the existentialists, that is the root meaning of truth, and the conventional philosophical notions - involving relations between propositional representations and what they are supposed to represent - are entirely derivative from and dependent upon it.

Note some curious implications of this conception of truth. Truth is a self-determined relationship of deepening first-person acquaintance with reality in its transcendent otherness from oneself, of increasing first-person correspondence. Being so, it cannot ultimately be stated or put into words. All that is represented or put into words at best testifies of, or points to, or reflects, that relationship but cannot itself be that relationship. Hence all explicit knowledge by representation is rooted and grounded in a tacit knowledge by acquaintance. To receive and accredit information from another person about a certain situation ( $\mathrm{eg}$ to be told the truth you wish to learn) is ultimately to appeal to another person's acquaintance with the situation in question; the buck has to stop somewhere. The existentialist notion of truth hinges, therefore, upon the possibility of direct personal acquaintance with things, upon a fundamental 'disclosedness' of things to us (to use Heidegger's phrasing) - indeed, upon the possibility of direct mutual acquaintance and recognition by multiple persons.

\section{INESCAPABLE RESPONSIBILITY IN THE DETERMINATION OF TRUTH}

The existentialists would awaken us to our complicity in shaping and acknowledging the world to be what we take it 'naturally' and 'objectively' to be quite apart from us. No matter how 'objectively given' a truth may seem to be (as reflected, say, in its formal mode of expression), it has to come back someplace to someone's determination and acknowledgement of it, to be 'objectively given.' And because of that peculiar 'fact' it is not (or is never wholly) objectively given. The objective voice dis- 
guises our existential participation in the determination of truth. All truth determined to be truth by somebody (and ultimately by you and me). All truth is acknowledged truth. (Even truth acknowledged by others, to be truth, must be acknowledged by us as well.) We bear responsibility for acknowledging all truth; it implicates us. Indeed, there is a sense in which we have no relation to truth apart from our determination and acknowledgement of it. (Heidegger would put it even more radically: it is not that the determination of truth rests with us - implying that we could, if we chose, opt not to participate in it - but that it is so fundamental to our being that we cannot escape participating in the determination of truth. The possibility of avoiding, covering over, or distorting the truth presupposes in some sense our prior acquaintance with it: untruth presupposes truth.)

\section{THE PROBLEM OF SUBJECTTVISM AND ITS SOLUTION}

But then does that not make truth simply a function of our self-determination and personal acknowledgment? Does that not make truth merely our own creation? Indeed, does that not make truth simply subjective? No, it does not, though most superficial interpretations of the existentialists make them out to be saying just that. (Many readers of Kierkegaard's Concluding unscientific postscript neglect to take into account a passage which follows a few pages after the infamous claim that truth is subjectivity which goes on to explain how subjectivity is untruth! The point is that, de jure, subjectivity is to become truth, but. de facto, subjectivity is untruth.) However, the possibility that what at any given moment we take to be truth is merely subjective and not truth is very real, and the attainment of truth can never be taken for granted. More precisely, the likelihood is that very much of what we take to be truth is not truth but subjectivity in one respect or another, coloured by individual predeliction and shaped by cultural frames of reference. (Heidegger claims that all our participation in truth is simultaneously and ineradicably a participation in untruth as well.) The crucial factor is the human capacity for transcendence - for stretching (or being stretched) beyond one's own subjectivity, to become aware of and be in rapport with realities that transcend the self - and a passionate care for its achievement.

Strictly speaking, this transcendence is a positive transcendence - something more than and decidely different from the negative transcendence of the subject that is so strongly stressed by Sartre. The point is that for us to be in rapport with realities that transcend ourselves, we must not only have our own personal awareness of things - brought out so clearly by Sartre - but that awareness must be of things as they truly are and not just as we happen, or as someone else happens, for the 
moment, to be seeing them. We must be capable in some measure of ascertaining the propriety and justness of our awareness of things, and thus of glimpsing the gap between our notion of them and what they are in truth, that is glimpsing what they are in their transcendence beyond our mental representation of them - but not so transcendent that rapport, that entry into their presence, becomes impossible.

Were we incapable of this transcendence, this becoming present to things in themselves, truth would indeed simply be a matter of self-determined subjectivity. And in so far as we sceptically doubt this capacity in ourselves and others, that is the conclusion we come to; attainment of truth becomes impossible and, in the judgement of some, airy nonsense - or a disguise for exerting our arbitrary will to power over others. Sceptical doubt of truth itself disables the achievement of truth. Note here the curiously indispensible cognitive role of faith in a certain sense: if we did not believe ascertaining the truth were possible, we would make no effort to ascertain it. More: if we did not have intimations of hidden truth and faith in them, and faith in our capacity to follow them up responsibly, we could make no progress in finding it. It follows that affirmation of this capacity of transcendence in ourselves and others is itself an expression of faith - of faith in faith in this generic, cognitive sense. It cannot authentically be voiced in an impersonal, 'objective' mode. It is necessarily self-accredited.

It is only by virtue of our self-accredited ability to recognize transcendence in a person or in a particular person's judgement when we see it that we lay claim to truth. More specifically, it is only by virtue of our own self-accredited transcendence, our self-accredited achievement of having come to know something for ourselves, that we recognize transcendence in another as well as other realities beyond ourselves.

Thus, contrary to what is often thought, the existentialists (at least the ones I seek to represent) do not do away with transcendent reality. They are not non-realists. Nor do they reject the notion of objectivity. (What they reject is the formal mode of objectivity as an equivalent to the authentic achievement of objectivity - in the sense of ascertaining the nature of the object itself - and as an attempt to circumvent the necessary task of participating, oneself, in the determination of meaning and truth.) Rather, they contend that realism and authentic objectivity make no sense apart from the inner work of passionate self-transcendence, of bringing oneself progressively into conformity with reality. Truth is a personal achievement, demanding an ascetic overcoming of what inwardly stands in the way of its recognition and acknowledgement. 4 


\section{Endnotes}

1. Kierkegaard's views on the nature of truth are most fully developed in Soren Kierkegaard (1941), especially Book Two, Parts One and Two. Two excellent secondary discussions are C Stephan Evans (1983:115-135) chapter seven Truth and subjectivity', and Louis Mackey (1969:31-57).

Heidegger (1977:117-141) explicitly discusses truth in his essay, 'On the essence of truth', and in his book, The basic problems of phenomenology (Heidegger 1982:213-224) in section 18: 'Assertorial truth: The idea of truth in general, and its relation to the concept of being'.

Jaspers' (1986:230-235) treatment of truth may be found in Basic philosophical writings, Part Four: 'What is truth?'.

Marcel's (1960) most explicit discussions of truth are found in The mystery of being (1960:58-70) and 'Truth and freedom' and 'Truth and concrete situations', both in Tragic wisdom and beyond (1973:80-90, 91-102 respectively).

It should go without saying that attempts to understand these discussions of truth should take into account the larger philosophical context established by these particular writers' works.

2. One of the finest brief surveys extant of epistemological theories, including theories of truth (though not including existential theories of truth), is that of Paul K Moser and Arnold Vander Nat (1987:3-22), Human knowledge: Classical and contemporary approaches.

3. What is implied by his stated views (at least those of 'the early Sartre') is a curious contradictory mixture of realism and subjective idealism: Realism with regard to fundamental ontology and a radically subjective idealism with regard to meaning. On the one hand, his fundamental ontology - bifurcating being-foritself or human subjective understanding from being-in-itself or objective reality (which lies ineffably beyond all humanly meaningful characteriza-tion) - appears to presuppose the traditional conception of truth as correspondence (correspondence between Sartre's ontological propositions and the fundamental structure of being). On the other hand, his analysis of ordinary human affirmations (which his fundamental ontology is supposed somehow to transcend) presupposes truth as subjective coherence or authenticity (meaning: subjective selfconsistency plus a kind of negative or inverted correspondence with being-itself, a kind of perpetual noncoincidence or, as he puts it, a nihilation). In consequence, to be authentic, a statement (again, Sartre's ontological statements are apparently excepted) can make no appeal to an objective order of being as the ground of its meaning but must instead selfconsciously reflect its basis in the ultimately arbitrary, perpetually unstable projection of its author's subjectivity - 
which is to say: to be authentic, it must somehow reflect its ultimate groundlessness. Thus, it can be affirmed authentically only in the mode of never (quite) being affirmed; it can never be affirmed univocally. With the exception of some of the literary existentialists, perhaps, no other existentialist holds to these contradictory views of Sartre.

4. In this respect they link up with several pre-modern traditions of thought - particularly broadly Platonist criticisms of Aristotelian thought, such as those articulated by medieval monastic critics of the largely Aristotelian scholasticism which came to dominate the medieval universities. See Jean Leclerq (1974), The love of learning and the desire for God, especially chapter IX; and Steven Ozment (1980:73-82), The age of Reform: 1250-1550.

\section{Works cited}

Evans, C S 1983. Kierkegaard's fragments and postscript: The religious philosophy of Johannes Climacus. Atlantic Heights: Humanities Press International.

Heidegger, M 1977. On the essence of truth, tr by John Sallis, in Heidegger, M, Basic writings, 117-141. New York: Harper and Row.

--- 1982. The basic problems of phenomenology, tr by Albert Hofstader. Bloomington: Indiana University Press.

Jaspers, K 1986. Basic philosophical writings ed by Leonard, H E, Erlich, E, \& Pepper G E. Athens: Ohio University Press.

Kierkegaard, S 1941. Kierkegaard's concluding unscientific postscript, tr by Swenson, D F \& Lowrie, W. Princeton: Princeton University Press.

Leclerq, J 1974. The love of leaming and the desire for God, tr by Misrahi, C. New York: Fordham Press.

Mackey, L 1969. Kierkegaard and the problem of existential truth, in Gill, J H (ed), Essays on Kierkegaard, 31-57. Minneapolis: Burgess Publishing Co.

Marcel, G 1960. The mystery of being, vol 1, tr by Fraser, G S. London: The Havrill Press.

--- 1973. Tragic wisdom and beyond, tr by Jolin, S \& McCormick, P. Evanston: Northwestern University Press.

Moser, P K \& Vander Nat, A 1987. Human knowledge: Classical and contemporary approaches. New York: Oxford University Press.

Ozment, S 1980. The age of reform: 1250-1550. New Haven: Yale University Press. Sartre, J-P 1956. Being and nothingness, tr by Barnes, H. New York: Philosophical Library.

--- 1947. Existentialism, tr by Frechtman, B. New York: Philosophical Library. 
Sartre, J-P 1992. Truth and existence, tr by Van den Hoven, A and ed by Ronald Aronson. Chicago: University of Chicago Press. 